Southern Illinois University Carbondale

OpenSIUC

Articles

Department of Plant, Soil, and Agricultural Systems

$8-2003$

\title{
Identification and Use of Actinomycetes for Enhanced Nodulation of Soybean Co-Inoculated with Bradyrhizobium japonicum
}

\author{
A. K. Gregor \\ Brian Klubek \\ Southern Illinois University Carbondale \\ E. C. Versa
}

Follow this and additional works at: http://opensiuc.lib.siu.edu/psas_articles

Preprint version.

Published in Canadian Journal of Microbiology, vol.49, no.8, pp.483-491, at doi:10.1139/w03-061.

\section{Recommended Citation}

Gregor, A. K., Klubek, Brian and Versa, E. C. "Identification and Use of Actinomycetes for Enhanced Nodulation of Soybean CoInoculated with Bradyrhizobium japonicum." (Aug 2003).

This Article is brought to you for free and open access by the Department of Plant, Soil, and Agricultural Systems at OpenSIUC. It has been accepted for inclusion in Articles by an authorized administrator of OpenSIUC. For more information, please contact opensiuc@lib.siu.edu. 


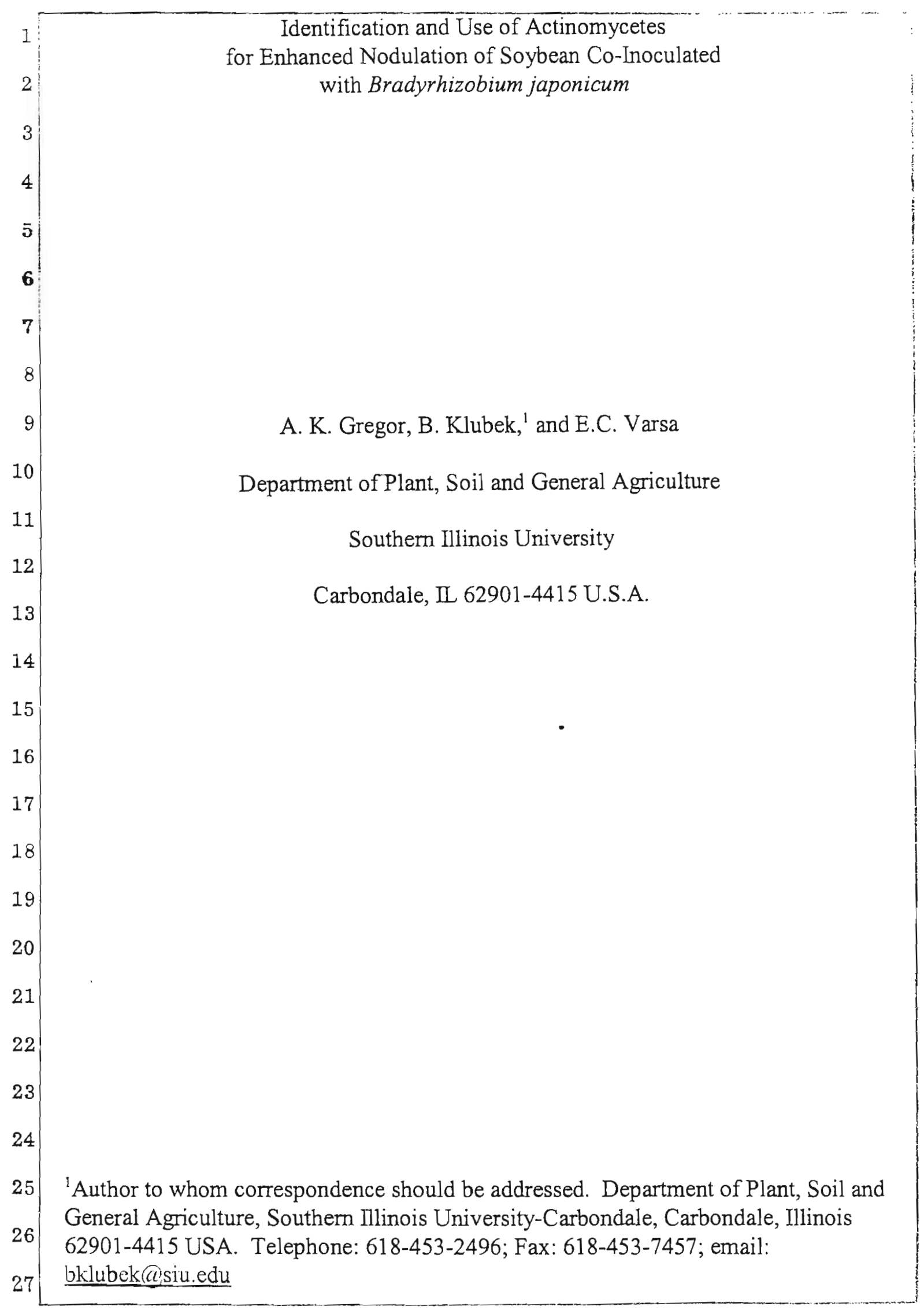




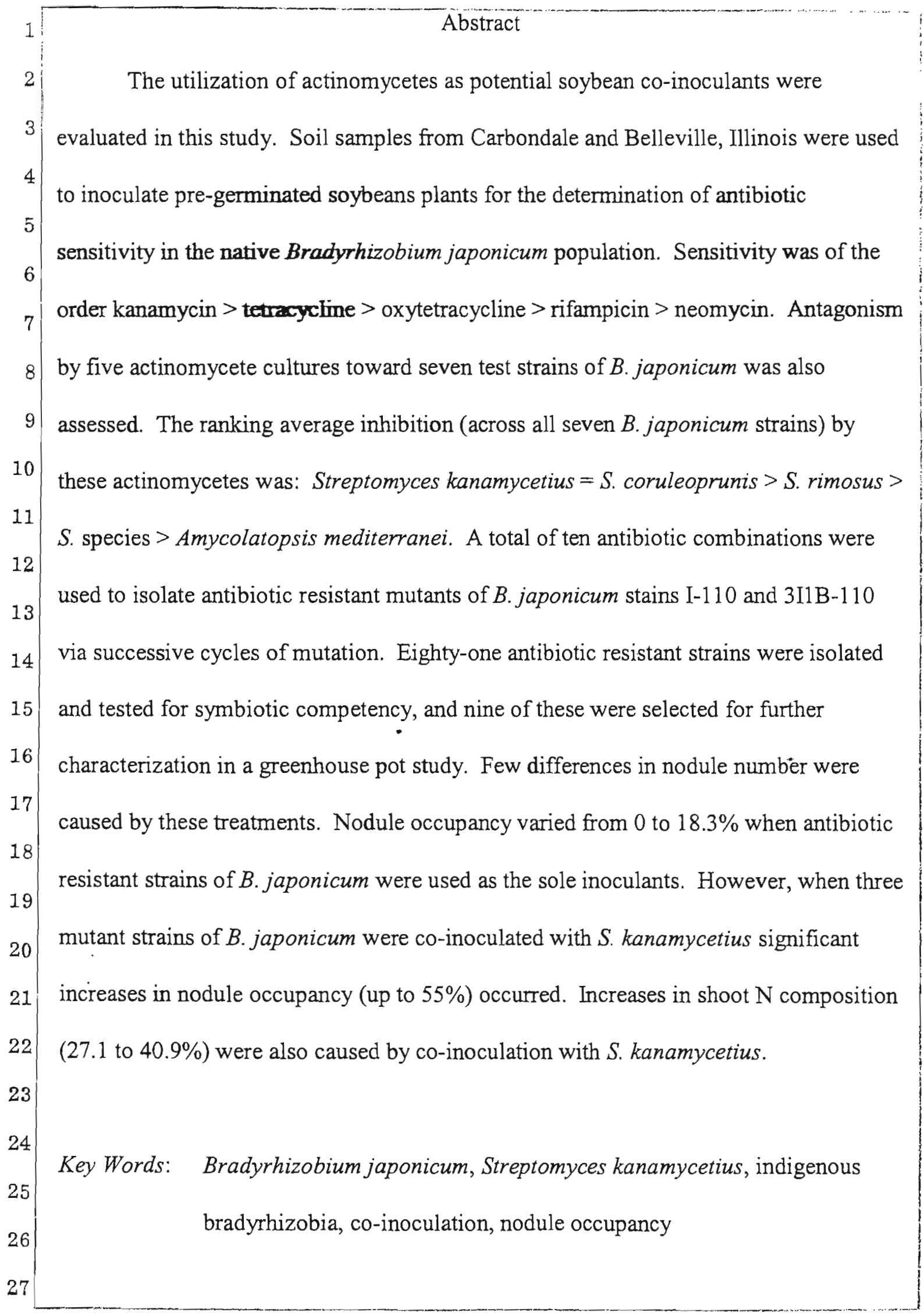




\section{Introduction}

Many nitrogen fixing bacteria convert gaseous nitrogen $\left(\mathrm{N}_{2}\right)$ to ammonia contributing to an important source of plant-available soil nitrogen. Bradyrhizobium japonicum forms a symbiotic relationship with soybean [Glycine max (L.)], resulting in biological nitrogen fixation. In Illinois it is estimated that 50 to 60 miltion doltars of murogen fertilizer credit is assigned on a yearly basis to soybean-com or soybean-wheat rotations. Assuming an average seed nitrogen content of $5.5 \%$, the estimated saving in nitrogen fertilizer costs is an additional 125 million dollars. Increasing seed nitrogen content could provide additional value as a protein supplement in foods and feeds.

Superior $\mathrm{N}_{2}$ fixing strains of Bradyrhizobium have been identified. However, highly competitive native soil bradyrhizobia limit the ability to control infection of soybean roots by an added inoculum strain. This is referred to as the Bradyrhizobium competition problem (Streeter 1994; Sadowsky and Graham1998). Successful inoculation of soybean is dependent upon overcoming competition of native bradyrhizobia and the establishment of the applied strain in soil.

B. japonicum serocluster 123, including the serogroups USDA 123, 127 and 129 (Schmidt et al. 1986), alone inhabits 50 to $90 \%$ of soybean nodules in the Midwestern USA (Damirgi et al. 1967; Ellis et al. 1984; Kapusta and Rouwenhorst 1973; Moawad et al. 1984). These serogroups are very competitive (Cregan et al. 1989; Ellis et al. 1984; Ham et al. 1971; Klubek et al. 1988) and may be inefficient in $\mathrm{N}_{2}$ fixation (Caldwell and Vest 1970; Ham 1980).

Inoculation with $B$. japonicum has been successful in increasing soybean nodulation with increases in plant fresh weight, seed protein and seed yield in soils with 
1 a low or absent native population (Abel and Erdman 1964; Caldwell and Vest 1970).

2 However, in soils with an established bradyrhizobial population, competition severely

3 limits nodulation by an inoculum and it is not easily enhanced (Ham et al. 1971; Kapusta and Rouwenhorst 1973; Weaver and Frederick 1974; Thies et al. 1992).

5

6

McLoughlin et al. (1990) used inoculum levels of $10^{8}$ cells per $2.5 \mathrm{~cm}$ length of row, and obtained a nodule occupancy of less than $42 \%$ with fittle persistence in the soil.

Ellis et al. (1984) found that the application of high levels of an applied strain increased the population size of that strain in soil but did not increase nodule occupancy.

Additionally, Brockwell et al. (1987) and Roughley et al. (1993) found over 90\% of their inoculum died within twenty-four hours of seed application.

The use of bactericidal agents has been shown to inhibit native bradyrhizobia. Hossain and Alexander (1984) found that the addition of the fungicide benomyl and the antibiotics erythromycin and streptomycin effectively enhanced colonization of soybean, when inoculated with"a strain of Bradyrhizobium resistant to these antimicrobial compounds. These antimicrobial agents were able to effectively reduce predation by protozoa or competition by native bradyrhizobia and allow the introduced strain to nodulate soybean. Jones and Giddens (1984) found that fungicide-resistant mutants of $B$. japonicum USDA strain 110, when used with the appropriate fungicide, experienced enhanced survival in the soil and the bacterial counts within the nodules were increased. Further studies by Li and Alexander (1986) used streptomycin amendments to the soil to limit the growth of Sinorhizobium meliloti allowing the resistant inoculum strain to increase nodule number and occupancy versus the treatment without the antibiotic. 


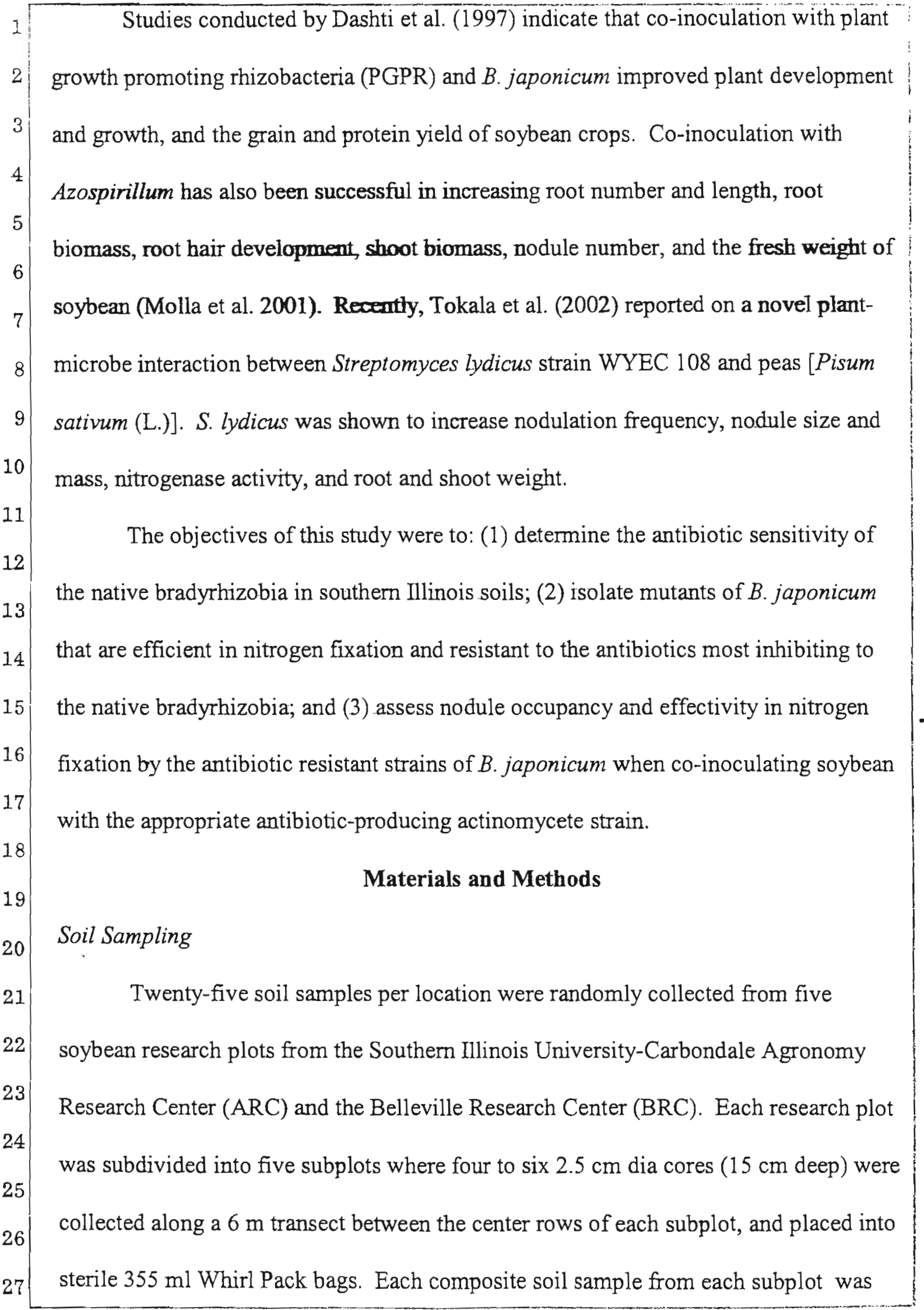


I placed in a portable cooler layered with polyfoam refrigerant packs until returned to the

laboratory where they were stored at $5^{\circ} \mathrm{C}$ until used. The soils at the ARC are classified

as a Stoy silt loam (fine-silty, mixed, mesic, Aquic Hapludalf), and a Weir silt loam

4

(fine, smectitic, mesic, Typic Epiaqualf). The soils at the BRC are classified as a

5

Cowden silt loam (fine, smectitic, mesic, Vertic Albaqualf), a Rushville silt loam (fine,

6 smectitic, mesic, Typic Albaqualf), and a Clarksdale sitt loam (fine, smectitic, mesic, Udollic Endoaqualf). Previous crop histories of the ARC sampled plots were either a corn [Zea mays (L.)]-soybean [Glycine max (L.)] or a corn-soybean-sorghum [Sorghum

bicolor (L.)] rotation. The BRC plots had been in either: (1) a soybean-wheat [Triticum aestivum (L.)] or a com-soybean-wheat rotation.

Testing for intrinsic resistance

Soybean (LS90-1920, a cultivar developed in the SIUC soybean breeding program, Schmidt et al.1999) were grown in washed vermiculite under a 16 hr photo period with fluorescent lighting at the SIUC Horticulture Research Center greenhouse, Carbondale, Illinois. Seven days after planting, $10 \mathrm{~g}$ of each soil sample were mixed with a sterile $90 \mathrm{ml}$ dilution blank, shaken for 1 minute, and used as an inoculum $(1 \mathrm{ml}$ per plant). Ten plants (replications) were used for each soil sample. The inoculated soybean plants were grown for an additional 35 days and watered as necessary with a nitrogen free mineral nutrient solution. At harvest the plants were removed from their pots with the plant shoots cut just above the roots. The root system of each plant was then washed free of vermiculite, blotted dry and placed in a sterile Whirl Pak bag and stored in a freezer at $-20^{\circ} \mathrm{C}$. The soybean nodules from these root samples were used to assess the sensitivity of the native $B$. japonicum population to selected antibiotics. 
$I$

Following the procedure of Lieberman et al. (1986), 16 nodules of each root were randomly selected, washed, surfaced sterilized with $20 \%(\mathrm{v} / \mathrm{v})$ bleach and $70 \%$ (v/v) ethanol, rinsed three times with distilled water, cnushed, and plated on yeast extract mannitol (YEM) agar supplemented with one of the following antibiotics at a concentration of $100 \mu \mathrm{g} / \mathrm{ml}$ : neomycin $(\mathrm{N})$, oxytetracycline (O), rifampicin (R), tetracycline (T), or kanamycin (K). Cycloheximide was also added to all of the growth media at $200 \mu \mathrm{g} / \mathrm{ml}$ to suppress the growth of fungi. A set of YEM plates without antibiotics were used as a positive control. All plates were grown for 7 to 14 days at $28^{\circ} \mathrm{C}$ and scored for growth as compared to the control. The number of developing colonies on the YEM-antibiotic plates divided by the number of developing colonies on the complementary YEM-control plates multiplied by 100 determined the percent intrinsic resistance by the native bradyrhizobia.

\section{Testing of antagonistic strains}

Actinomycete cultures that produce the antibiotics used in nodule typing . (described above) were obtained from the American Type Culture Collection (ATCC): Amycolatopsis mediterranei ATCC \#13685 (rifampicin), Streptomyces coeruleoprunus ATCC \#43681 (neomycin), Streptomyces kanamycetius ATCC \#12853 (kanamycin), Streptomyces rimosus sub sp. rimosus ATCC \#33022 (oxytetracycline), and Streptomyces sp. ATCC \#11652 (tetracycline). The test strains of B. japonicum used were USDA strains I-1 10, 3Il b-110, 3Illb-76, 3Ilb-24, 123, and 127, and strain An-5 (a streptomycin resistant strain of serogroup 123 received from Dr. R.M. Zablotowicz, the USDA Weed Science Laboratory, Stoneville, MS). Each test strain was grown to stationary phase (5 days) in $100 \mathrm{ml}$ of YEM broth at room temperature on a tabletop 
shaker at $170 \mathrm{rpm}$. YEM agar plates were spread with $0.1 \mathrm{ml}$ of broth culture and then streaked with an actinomycete culture in the form of a plus sign. A YEM agar plate inoculated with individual $B$. japonicum test strains was used in all cases as a positive control allowing a visual comparison. Following five days of growth at $28^{\circ} \mathrm{C}$, inhibition by the actinomycete cultures in the four corners of the ' + ' pattern was visually rated on a scale of 1 to 10 and statistically analyzed after arcsine transformation (Little and Hills 1978).

\section{Selection of antibiotic resistant strains}

Antibiotic resistant mutants of $B$. japonicum strains $I-110$ and $3 \mathrm{I} 1 \mathrm{~B}-110$ were obtained via successive cycles of mutation (Cooper 1979), on YEM agar plates amended with any combination of two antibiotics: kanamycin + neomycin $(\mathrm{KN})$, kanamycin + tetracycline (KT), kanamycin + rifampicin (KR), kanamycin + oxytetracycline $(\mathrm{KO})$, oxytetracycline + tetracycline $(\mathrm{OT})$, neomycin + tetracycline (NT), rifampicin + tetracycline (RT), neomycin + oxytetracycline (NO), rifampicin + oxytetracycline (RO), and rifampicin + neomycin (RN). The $B$. japonicum strains were grown in $100 \mathrm{ml}$ YEM broth culture at room temperature on a tabletop shaker at 170 rpm for 5 days, as previously described. YEM agar plates amended with $12.5 \mu \mathrm{g} / \mathrm{ml}$ of each antibiotic combination listed above were inoculated with $0.1 \mathrm{ml}$ of broth culture. The plates were then incubated at $28^{\circ} \mathrm{C}$ for 7 to 14 days. Individual colonies growing on the plates of each antibiotic combination were transferred to new plates containing $25 \mu \mathrm{g} / \mathrm{ml}$ of each antiobiotic combination streaked for isolation, and grown as previously described. This step-wise successive transfer of isolates was followed until five different isolates were obtained from each antibiotic combination at a final 
1

2 3 activity concentration of $100 \mu \mathrm{g} / \mathrm{ml}$.

Testing of antibiotic resistant strains for competency in nodulation and $\mathrm{N}_{2}$ - fixation

A 0.9 meter by 3.4 meter greenhouse bench was enclosed in clear plastic canopy to eliminate potential contamination of soybean plants by $B$. japonicum bearing. Lights were installed under the canopy to allow for a 16 hour photo period. The soybean plants (LS 90-1920) were grown using washed vermiculite in $12 \mathrm{~cm} \times 8.5 \mathrm{~cm}$ diameter plastic cups modified with three drainage holes. A lattice board comprised of $2.5 \mathrm{~cm}$ wide wood strips was placed on top of the greenhouse bench supported by the bench's sides. The cups were inserted in the lattice holes $(7 \mathrm{~cm} \times 7 \mathrm{~cm})$ suspending them above the bench top. Three surface sterilized seeds (an eight minute exposure to $10 \% \mathrm{v} / \mathrm{v}$ $\mathrm{H}_{2} \mathrm{O}_{2}$ ) were planted in each pot and this was reduced to one seedling per pot after approximately 5 days after seeding. The plants were inoculated at one week after planting with $1 \mathrm{ml}$ of a 7 day old broth (YEM) culture of an antibiotic resistant strain of B. japonicum. The wild type strains $\mathrm{I}-110$ or $3 \mathrm{I1b}-110$ were included as controls for each trial evaluating eight to ten resistant strains. Each inoculum treatment was replicated five times and watered as needed with a $\mathrm{N}$ free mineral nutrient solution. In total, nine trials were required to assess 81 isolated antibiotic resistant strains. Harvesting occurred at 35 days after inoculation to assure for the development of functional nodules.

At harvest, plants were removed from their pots and the plant shoots were cut just above the root as previously described. The roots were shaken free of vermiculite, placed in $946 \mathrm{~cm}^{3}$ mason jars, and sealed with a screw capped lid. One hundred $\mathrm{cm}^{3}$ of 
air was removed and replaced with $100 \mathrm{~cm}^{3}$ acetylene using a $50 \mathrm{~cm}^{3}$ syringe with a 25 gauge needle. The jars were incubated for one hour at room temperature in the greenhouse. A $10 \mathrm{~cm}^{3}$ sample was then removed and analyzed for ethylene by gas chromatography (Hardy et al. 1968). Plant shoots were dried at $70^{\circ} \mathrm{C}$ for 48 hours, ground and analyzed for total $\mathrm{N}$ by Brookside Laboratories, New Knoxville, Ohio. Nodules were counted and nodule occupancy was determined following the procedure of Lieberman et al. (1986). The number of developing colonies on the YEM-antibiotic plates divided by the number of developing colonies on the complementary YEMcontrol plates multiplied by 100 gave the percent nodule occupancy by the applied strain.

Soil pot co-inoculation greenhouse study

Approximately $0.06 \mathrm{~m}^{3}$ of soil ( 0 to $15 \mathrm{~cm}$ deep) was obtained from the SIU-C Agronomy Research Center. The soil is classified as a Stoy silt loam, and corn was produced at that site the previous year.

The soil was allowed to air dry on a greenhouse bench, ground and analyzed for exchangeable potassium (Knudsen et al., 1982), Bray P1 extractable phosphorus (Olsen and Sommers 1982) and pH (McLean 1982). These results are summarized in Table 1. Two hundred thirty, $12 \mathrm{~cm} \times 8.5 \mathrm{~cm}$ cups were modified with three drainage holes and lined with cheese cloth on the bottom of each cup. The cups were then filled with the ground soil. Additionally, for a negative-nodulation control, ten cups were filled with soil amended with $75 \mathrm{mg} \mathrm{N}$ (as ammonium nitrate)/kg soil. The soils were moistened to field capacity as described by Sabey et al (2003).

S. kanamycetius and ten antibiotic resistant strains of B. japonicum selected for 
the co-inoculation study were grown in YEM broth as previously described. Fifty soybean seeds (LS 90-1920) were treated as follows: (1) $0.4 \mathrm{ml}$ of $10 \%(\mathrm{w} / \mathrm{v})$ gum acacia (used as a seed adhesive for the applied S. kanamycetius and/or B. japonicum cells) and $0.5 \mathrm{~g}$ activated charcoal (a coating of fine solid particles to avoid seed clumping) (non-inoculated control); (2) $0.3 \mathrm{ml}$ of $S$. kanamycetius broth culture followed by the addition of gum acacia and activated charcoal as previously described; (3) $0.3 \mathrm{ml}$ (each) of B. japonicum and S. kanamycetius followed by gum acacia and activated charcoal. The mean plate count of each inoculum strain is given in Table 2.

The inoculated seeds were immediately planted into the soil pots ( 3 seeds per pot for 10 replications per treatment) and randomized in a complete block design. Five days following emergence, each experimental unit (pot) was thinned to one seedling per pot.

Plants were watered as needed with potable water from the greenhouse, and a 16 hour photoperiod was used as previously described. Thirty-five days after planting the plants were removed from the soil with the plant shoots severed just above the root system. The roots were washed free of soil and placed in Whirl Pak bags and stored in a freezer at $-20^{\circ} \mathrm{C}$ until measurements could be made. Nodule number and occupancy was determined as previously described. Nodules were plated on YEM agar plates containing $\mathrm{KN}$ or $\mathrm{KT}(100 \mu \mathrm{g} / \mathrm{ml}$ per antibiotic), and YEM agar alone as a positive control. The plates were incubated 10 to 14 days and scored for growth. Plant shoots were dried at $70^{\circ} \mathrm{C}$ for 48 hours, ground to pass a 100 mesh sieve, and analyzed for total N by Brookside Laboratories, New Knoxville, Ohio. Statistical analysis

All of the data were analyzed by an Analysis of Variance (ANOVA), and mean 


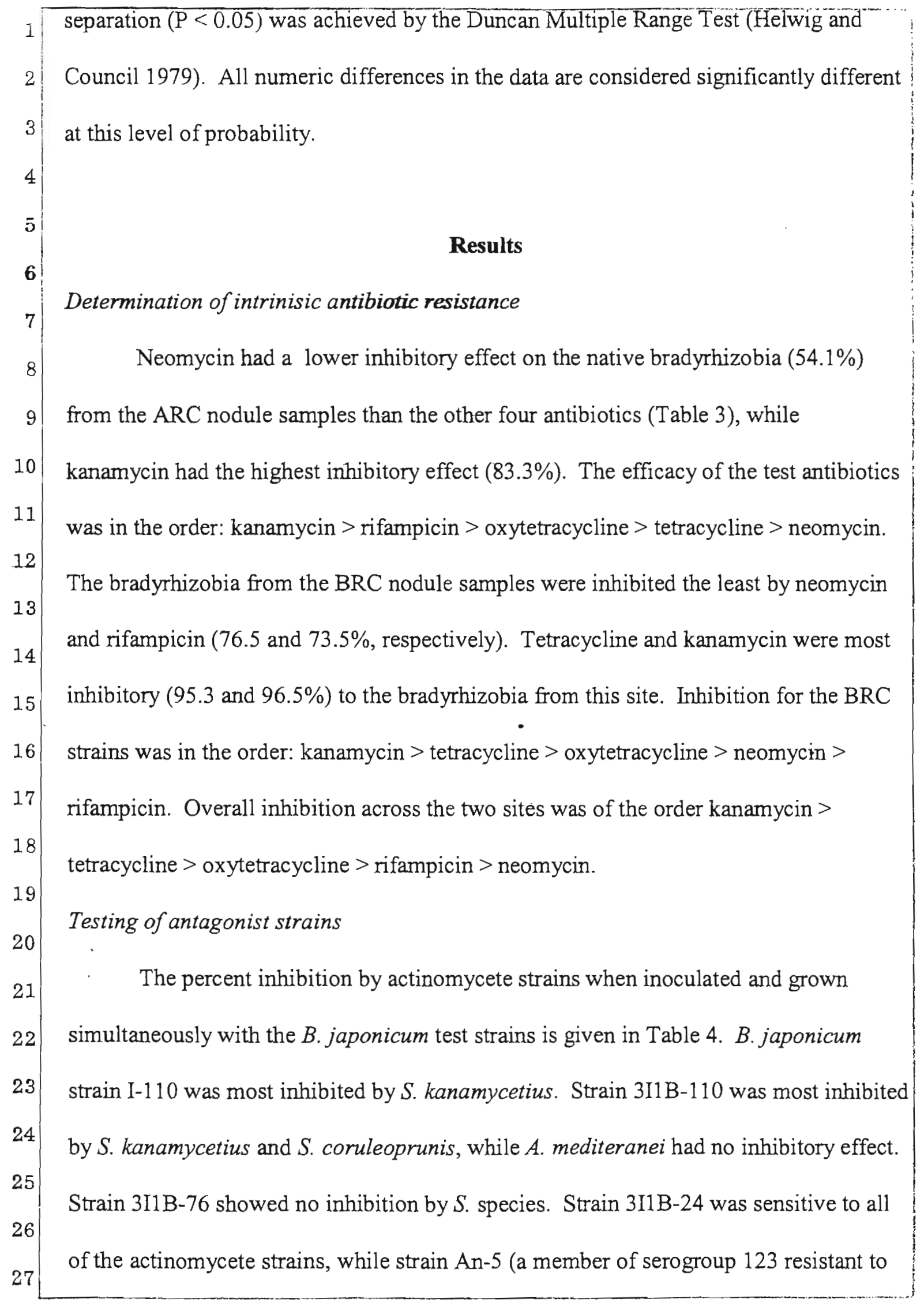


streptomycin) was equally inhibited by $A$. mediteranei, $S$. coruleoprumus, $S$.

kanamycetius and $S$. species although not inhibited by $S$. rimosus. Strain 123 was not inhibited by $S$. species, but was significantly inhibited by $S$. rimosus. Strain 127 was inhibited by $S$. coruleoprunus and $S$. kanamycetius and showed no inhibition by either $S$. rimosus or $S$. species. The average percent inhibition of $B$. japonicum by the five actinomycete strains was of the order $S$. coruleoprunus $>S$. kanamycetius $>S$. rimosus $>S$. species $>A$. mediteranei, ranging from 22 to $9.2 \%$ inhibition.

\section{Testing strains for competency in nodulation and $N_{2}$ fixation activity}

A total of 81 antibiotic resistant strains of B. japonicum were isolated and evaluated in nine greenhouse trials of symbiotic competency. Table 5 only summarizes the results of two trials from which 9 strains were selected for the soil-pot greenhouse study. In all of the other trials the antibiotic resistant strains had reduced symbiotic competency and these were discarded. Differences between the $\mathrm{KN}$ antibiotic resistant strains and the parental wild type strains of $B$. japonicum for nodule number and occupancy, shoot $\mathrm{N}$ content, and nitrogen fixation (acetylene reduction) activity were measured in Trial 1. In Trial 2, strain KT 3I1B-1 was greater than strains KT3I1B-2 and-3 in nodule occupancy but not in the other characteristics of symbiotic competency. Most of the soybean plants inoculated by the antibiotic resistant strains in Trials 1 and 2 had a nodule number count, shoot $\mathrm{N}$ content and nitrogen fixation (acetylene reduction) activity that were equal to or greater than the soybeans inoculated with the parental wild type strains.

\section{Soil-pot greenhouse study}

With the exception of treatment $\mathrm{KNI}-110-2$ and the $\mathrm{N}$ fertilizer control, there 
were no differences among treatments for nodule number (Table 6). The KNI-110-2

treatment had a higher nodule count than all other treatments while the $\mathrm{N}$ fertilizer control (as expected) had the lowest nodule count. Nodule occupancy varied from 0 to $18.3 \%$ when the $\mathrm{KN}$ or $\mathrm{KT}$ strains were used as sole inoculants. However, an increase in nodule occupancy occurred with co-inoculation by $S$. kanamycetius and strain KNI$110-1, \mathrm{KNI}-110-5$, or KN311B-2, improving from $1.0,6.6$ and $0 \%$ to $44.8,48.0$, and $55.0 \%$, respectively. The $S$. kanamycetius treatment resulted in a nodule occupancy that was not different from the non-inoculated control. An increase in shoot $\mathrm{N}$ content over the non-inoculated control by the co-inoculum treatments of $S$. kanamycetius and strains KNI-110-1, KN3I1B-2, or KT3I1B-3 was determined $(3.13,3.05$, and $3.24 \%$, respectively). However, inoculation by strains KN3I1B-3, KT3I1B-1 and KT3I1B-2 without S. kanamycetius also resulted in a higher shoot $\mathrm{N}$ contents $(2.99,3.21$, and $3.07 \%$ respectively) over the non-inoculated control treatment. All other inoculum treatments were equivalent in shoot $\mathrm{N}$ content to the non-inoculated control.

\section{Discussion}

The main objectives of this study were to assess the antibiotic sensitivity of the native bradyrhizobia in southem Illinois soils, and to develop antibiotic resistant strains of B. japonicum which may be used to co-inoculate soybean crops with the appropriate antibiotic-producing actinomycete strain.

At the $\mathrm{ARC}$ and $\mathrm{BRC}$ research centers, the native bradyrhizobia showed greater sensitivity to kanamycin than neomycin despite their similarities in modes of action. This may be attributed to a plasmid encoded resistance to neomycin, but not kanamycin, at these locations and/or the presence of streptomycetes which synthesize neomycin or 
neomycin-like agents resulting in the selection for neomycin resistance. Tetracycline and oxytetracycline were similar in their degree of inhibition at both the ARC and BRC locations. These results suggest that varying populations of actinomycetes (which produce these antibiotics) exist at the Carbondale and Belleville locations. However, similar results for rifampicin inhibition were obtained for both locations, implying similar populations of Amycolatopsis mediterranei may exist at both field sites.

Collectively, the inhibition of $B$. japonicum from soybean nodules derived from these two locations was not identical, indicating that antibiotic sensitivity varies from location to location. However, on average, kanamycin was most effective in suppressing the growth of the native bradyrhizobia. Marciniak (1984) reported a greater incidence of intrinsic resistance to streptomycin, kanamycin and rifampicin at Brownstown, Ilinois but found a greater sensitivity by the native bradyrhizobia to these same antibiotics at Belleville, Flora and Vergennes, Illinois. Mueller et al. (1988) reported that the intrinsic resistance of $B$. japonicum isolated from South Carolina soils to antibiotics was of the order: streptomycin $\gg$ streptomycin + neomycin $>$ streptomycin + rifampicin $>$ kanamycin + rifampicin $=$ kanamycin + nalidixic acid. These authors concluded that intrinsic resistance by native bradyrhizobia was the norm for South Carolina soils.

The efficacy of the actinomycete cultures in suppressing the growth of the $B$. japonicum test strains was variable. On average, the lower antibradyrizobial activity expressed by $S$. species and $A$. mediteranei versus $S$. coeruleoprunis, $S$. kanamycetius, and $S$. rimosus when grown in the presence of the B. japonicum test strains (mimicking co-inoculation on the seed coat) suggests that the former strains require the 
1

accumulation of tetracycline/rifampicin for the suppression of $B$. japonicum growth.

The efficacy of $B$. japonicum antagonism expressed by $S$. coreuleoprunis, $S$.

kanamycetius, or S. rimosus apparently does not require the accumulation of neomycin,

kanamycin, or oxytetracycline, but rather may be associated with the direct suppression

of growth. It has been reported that different strains may show different intrinsic resistance patterns to the amtibiotic employed (Cole and Elkan 1979; Davis 1962;

Graham 1963). Consequently, a variety of intrinsic resistance patterns may result from different locations, strains, and experimental conditions. The use of a good antagonist strain as the co-inoculum was important for this study. Due to the variety of intrinsic resistance patterns that were observed, all combinations of kanamycin, neomycin, oxytetracycline, rifampicin, and tetracycline were used to isolate resistant mutants of $B$. japonicum strain I-110 and 3I1B-110.

Only nine isolated strains, resistant to either kanamycin + neomycin or kanamycin + tetracycline, were chosen for additional greenhouse studies. The remaining resistant strains produced few or no nodules indicating that resistance to the other combinations of selected antibiotics interfered with the root-hair infection process. Tetracycline and oxytetracycline are more aggressive protein synthesis inhibitors than neomycin and kanamycin (Stryer 1995.). The strains resistant to oxytetracycline plus neomycin or kanamycin, and neomycin plus tetracycline may have acquired an altered 30s subunit of rRNA to survive the mode of action of these antibiotics (Stryer 1995). A mutation of this kind would most likely lead to numerous alterations of proteins including the cell wall structure interfering with host recognition and eventual nodulation. Resistance to an antibiotic may also be due to an alteration of the antibiotic 
itself, rendering it nonfunctional, pumping the antibiotic out of the cell, or altering the

2 site of action of the antibiotic. The $\mathrm{KN}$ and $\mathrm{KT}$ strains summarized in Table 5 may have

3 evolved on these latter mechanisms without interfering with the root-hair infection process.

The variation in nodule occupancy, shoot $\mathrm{N}$ content, and nitrogen fixation (acetyiene reduction) activity may also be attributed to the acquisition of antibiotic resistance. Cole and Elkan (1979) have suggested that a potential for the loss of resistance characters exists for $B$. japonicum. Additionally, the failure to detect an applied inoculum labeled with multiple markers may also be due to slow growth and an inappropriate incubation period. Levin and Montgomery (1974) reported that $B$. japoncium is, in general, not susceptible to the loss of effectiveness in nodulation or efficiency in nitrogen fixation due to antibiotic resistance. The observed differences in shoot $\mathrm{N}$ content and nitrogen fixation (acetylene reduction) activity in this study may be related to the acquired resistance to kanamycin and/or neomycin which interferes withr nutrient transport (Stryer, 1995).

The addition of nitrogen as a fertilizer control was used to compare the differences in shoot $\mathrm{N}$ content between biologically fixed and applied N. Although this fertilizer treatment resulted in a higher $\mathrm{N}$ content than all other treatments, the benefits of soybean inoculation by strains KN311B-3, KT311B-1 and KT3I1B-2, and $S$. kanamycetius plus KNI-110-1, KN3I1B-2, or KT311B-3 were realized with a 19.6 to $29.6 \%$ increase in shoot $\mathrm{N}$ content over the non-inoculated control. For the latter three co-inoculum treatments, a 27.1 to $40.9 \%$ increase in shoot $\mathrm{N}$ content was determined over the same B. japonicum strains without $S$. kanamycetius. The increase in nodule 
occupancy by strains $\mathrm{KNI}-110-1, \mathrm{KNI}-110-5, \mathrm{KN} 3 \mathrm{I} 1 \mathrm{~B}-2$, and $\mathrm{KT} 3 \mathrm{I} 1 \mathrm{~B}-3$ when coinoculated with $S$. kanamycetius further demonstrates the potential synergistic benefits of co-inoculation by any combination of these strains. The $4 \%$ increase in nodule occupancy by strain KT3I1B-3 when co-inoculated with $S$. kanamycetius may also have contributed, in part, to the increase in shoot $\mathrm{N}$ content. Conversely, the lack of an increase in shoot $\mathrm{N}$ content by the co-inoculum treatment KN3I1B-3, KT3I1B-1, or KT3I1B-2 with $S$. kanamycetius suggests that any positive interaction between $S$. kanamycetius and a strain of $B$. japonicum may be highly specific. Thus, the most compatible strains of $B$. japonicum in association with $S$. kanamycetius offers the greatest potential for successful soybean inoculation.

The higher nodule number following inoculation with KNI-110-2 inoculum treatment did not result in an improvement in nodule occupancy by this strain or shoot $\mathrm{N}$ content. Although co-inoculation by this strain with $S$. kanamycetius reduced the number of nodules, it did improve nodule occupancy 2.7 fold and shoot $\mathrm{N}$ content by $9.8 \%$. It may also be that the strain caused an increase in nodule occupancy by a more efficient strain, resulting in a greater shoot $\mathrm{N}$ content, and also a reduction in the number of nodules required to fix $\mathrm{N}$. These results show that no relationship exits between nodule number and nodule occupancy or shoot $\mathrm{N}$ content, but that co-inoculation with $S$. kanamycetius may improve the occupancy of an applied strain.

The problem of successful soybean inoculation by an applied strain of $B$. japoncium still exists. It is clear from this study that the co-inoculation of soybeans with an appropriate actinomycete strain may be a novel approach in overcoming competition by the native bradyrhizobia, and the establishment of an applied strain. 


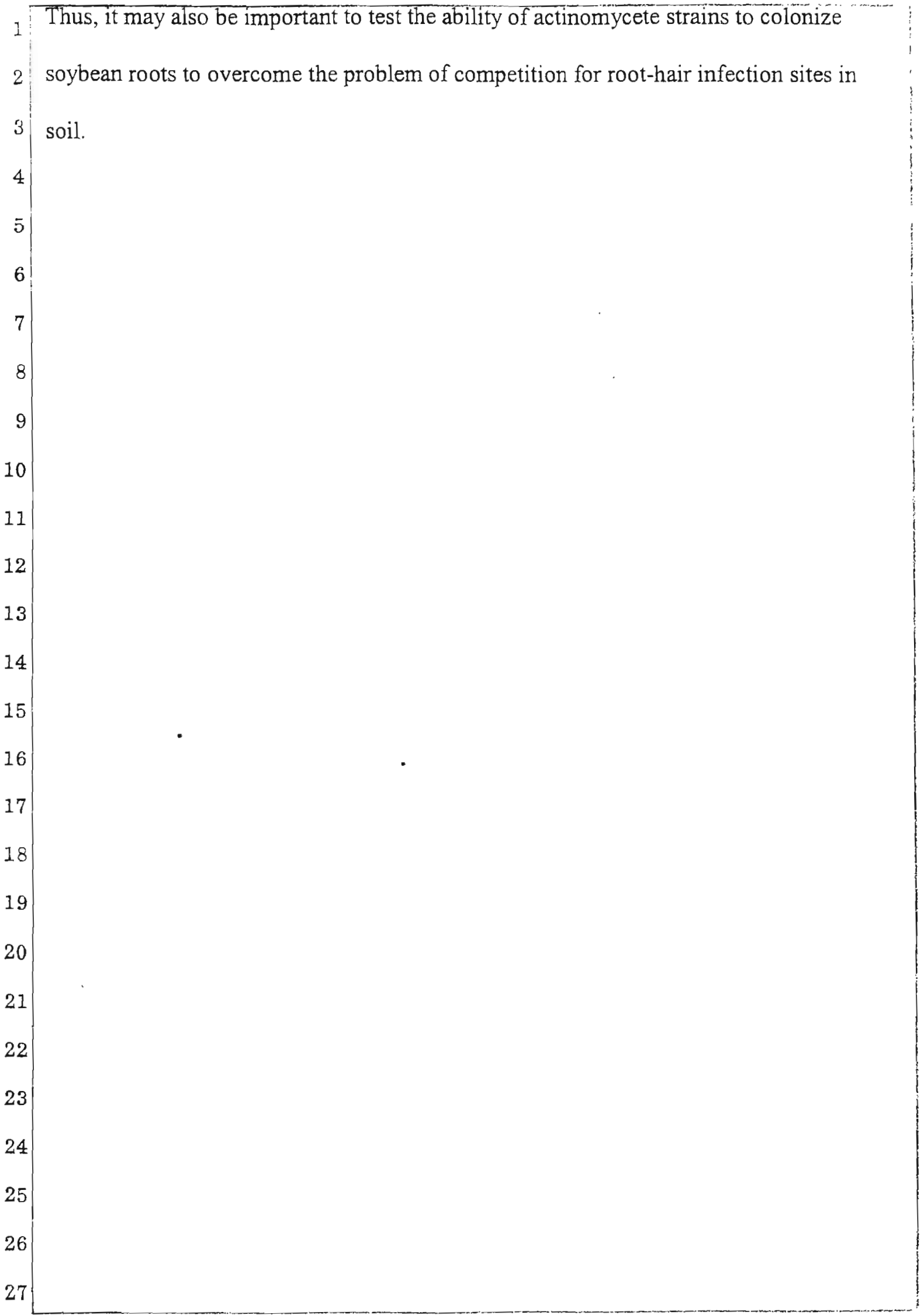




\section{Acknowledgments}

The authors thank K. Shimizu, E. White, and L. Lorton for their technical assistance, T. Wyciskalla for help with statistical analysis, and L. Hartline for help in the preparation of this manuscript. This research was supported by a grant from the Illinois Council on Food and Agricultural Research (C-FAR).

Abel, G. H., and Erdman, L.W. 1964. Response of Lee soybeans to different strains of Rhizobium japonicum. Agron. J. 56:423-424.

Brockwell, J., Roughley, R.J., Herridge, D.F. 1987. Population dynamics of Rhizobium japonicum used to inoculate three successive crops of soybean. Aust. J. Agric. Res. 38:61-74.

Caldwell, B.E., and Vest, G. 1970. Effect of Rhizobium japonicum strains on soybean yields. Crop Sci. 10:19-21.

Cole, M.A., and Elkan, G.H. 1979. Multiple antibiotic resistance in Rhizobium japonicum. App. Environ. Microbiol. 37:867-870.

Cooper, J.E. 1979. Rapid method for counting antibiotic-resistant rhizobia in soils. Soil Biol. Biochem. 11:433-435.

Cregan, P.B., Keyser, H.H., and Sadowsky, M.J. 1989. Host plant effects on nodulation and competitiveness of the Bradyrhizobium japonicum serotype strains constituting serocluster 123. Appl. Environ. Microbiol. 55:2532-2536.

Damirgi, S.M., Frederick, L.R., and Anderson, J.C. 1967. Serogroups of Rhizobium japonicum in soybean nodules as affected by soil types. Agron. J. 59:10-12.

Dashti, N. Zhang, F., Hynes, R., and Smith, D.L. 1997. Application of plant-growth promoting rhizobacteria to soybean [Glycine max (L) Merr] increases protein and dry matter under short-season conditions. Plant and Soil 188:33-41.

Davis, R.J. 1962. Resistance of rhizobia to antimicrobial agents. J. Bacteriol. 84:187188.

Ellis, W.R., Ham, G.E., and Schmidt, E.L. 1984. Persistence and recovery of Rhizobium japonicum inoculum in a field soil. Agron. J. 76:573-577.

Graham, P.H. 1963. Antigenic affinities of the root-nodule. J. Bacteriol. 84:187-188.

Ham, G.E. 1980. Interactions of Glycine max and Rhizobium japonicum. In Advances in Legume Science. Edited by R.J. Summerfield and A.H. Bunting. Royal Botanical Gardens, Kew, United Kingdom. pp. 289-296. 
Ham, G.E., Cardwell, V.B., and Johnson, H.W. 1971. Evaluation of Rhizobium japonicum inoculants in soils containing naturalized populations of rhizobia. Agron J. 63:301-303.

3 Hardy, R.W.F., Holsten, R.D., Jackson, E.K., and Burns, R.C. 1968. The acetyleneethylene assay of $\mathrm{N}_{2}$-fixation: laboratory and field evaluation. Plant Physiol. 43:11871207.

Helwig, J.R., and Council, K.A. 1979. The SAS User's Guide. SAS Institute, Inc., Raleigh, North Carolina. $474 \mathrm{p}$.

Hossain, A.K.M., and Alexander, M. 1984. Enhancing soybean rhizosphere colonization by Rhizobium japonicum. Appl. Environ. Microbiol. 48:468-472.

Kapusta, G., and Rouwenhorst, D.L. 1973. Influence of inoculum size on Rhizobium japonicum serogroup distribution frequency in soybean nodules. Agron. J. 65:916-919.

Klubek, B.P., Hendrickson, L.L., Zablotowicz, R.M., Skwara, J.E., Varsa, E.C., Smith, S., Islieb, T.G., Maya, J., Valdes, M., Dazzo, F.B., Todd, R.L., and Walgenback, D.D. 1988. Competitiveness of selected Bradyrhizobium japonicum strains in the midwestern USA Soils. Soil Sci. Soc. Am. J. 52:662-666.

Knudsen, D., Peters, G.A., and Pratt, P.F. 1982. Lithium, sodium, and potassium. In Methods of Soil Analysis. Part 2. Chemical and Microbiological Properties. Edited by A.L. Page, R.H. Miller, and D.R. Keeney. American Society of Agronomy, Madison, Wisconsin. Agronomy 9:225-246. Levin, R.A., and Montgomery, M.P. 1974. Symbiotic effectiveness of antibioticresistant mutants of Rhizobium japonicum. Plant and Soil 41:669-676. Li, D.-M., and Alexander, M. 1986. Bacterial growth rates and competition affect nodulation and root colonization by Rhizobium meliloti. Appl. Environ. Microbiol. 52:807-811.

Liberman, M.T., Zablotowicz, R.M., Davis-Omholt, N.P. 1986. Improved method of typing Bradyrizobium japonicum in soybean nodules. Appl. Environ. Microbiol. 51:715-719. Little, T.M., and Hills, F.J. 1978. Agricultural Experimentation. Design and Analysis. John Wiley and Sons, New York, NY. 300p. 
of Rhizobium japonicum (Kirchner) strain 110. M.S. thesis, Southem Illinois University-Carbondale, Carbondale, Illinois.

McLean, E.O. 1982. Soil pH. In Methods of Soil Analysis. Part 2. Chemical and Microbiological Properties. Edited by A.L. Page, R.H. Miller, and D.R. Keeney. American Society of Agronomy, Madison, Wisconsin. Agronomy 9:199-224.

McLoughlin, T.J., Alt, S.G., and Merlo, P.A. 1990. Persistence of introduced Bradyrhizobium japonicum strains in forming nodules in subsequent years after inoculation in Wisconsin soils. Can. J. Microbiol. 36:794-800.

Moawad, H.A., Ellis, W.R., and Schmidt, E.L. 1984. Rhizosphere response as a factor in competition among three serogroups of indigenous Rhizobium japonicum for nodulation of field-grown soybeans. Appl. Environ. Microbiol. 47:607-612.

Molla, A.H., Shamsuddin, Z.H., Halimi, M.S., Morziak, M. and Putek, A.B. 2001. Potential for enhancement of root growth and nodulation of soybean co-inoculated with Azospirillum and Bradyrhizobium in laboratory systems. Soil Biol. Biochem. 33:457463.

Muller, J.G., Skipper, H.D., Shipe, E.R., Grimes, L.W., and Wagner, S.C. 1988. Intrinsic antibiotic resistance in Bradyrhizobium japonicum. Soil Biol. Biochem. 20:879-882.

Olsen, S.R., and Sommers, L.E. 1982. Phosphorus. In Methods of Soil Analysis. Part 2. Chemical and Microbiological Properties. Edited by A.L. Page, R.H. Miller, and D.R. Keeney. American Society of Agronomy, Madison, Wisconsin. Agronomy 9:403430.

Roughley, R.J., Gemell, L.G., Thompson, J.A., and Brockwell, J. 1993. The number of Bradyrhizobium sp. (Lupinus) applied to seed and its effect on rhizosphere colonization, nodulation and yield of lupin. Soil Biol. Biochem. 25:1453-1458.

Sabey, B.R., Klubek, B.P., Chong, S-K., and Varsa, E.C. 2003. Introductory experimental soil science. Second edition. Stipes Publishing Company, Champaign, Illinois.

Sadowsky, J.J., and Graham, P.H. 1998. Soil biology of the Rhizobiaceae. In The Rhizobiaceae. Molecular Biology of Model Plant-Associated Bacteria. Edited by H.P. Spaink, A. Kondorosi, and P.J.J. Hooykaas. Kluwer Academic Publishers, Dordrecht, The Netherlands. pp. 155-172.

Marciniak, W.H. 1984. Isolation, characterization, and recovery of antibiotic mutants 


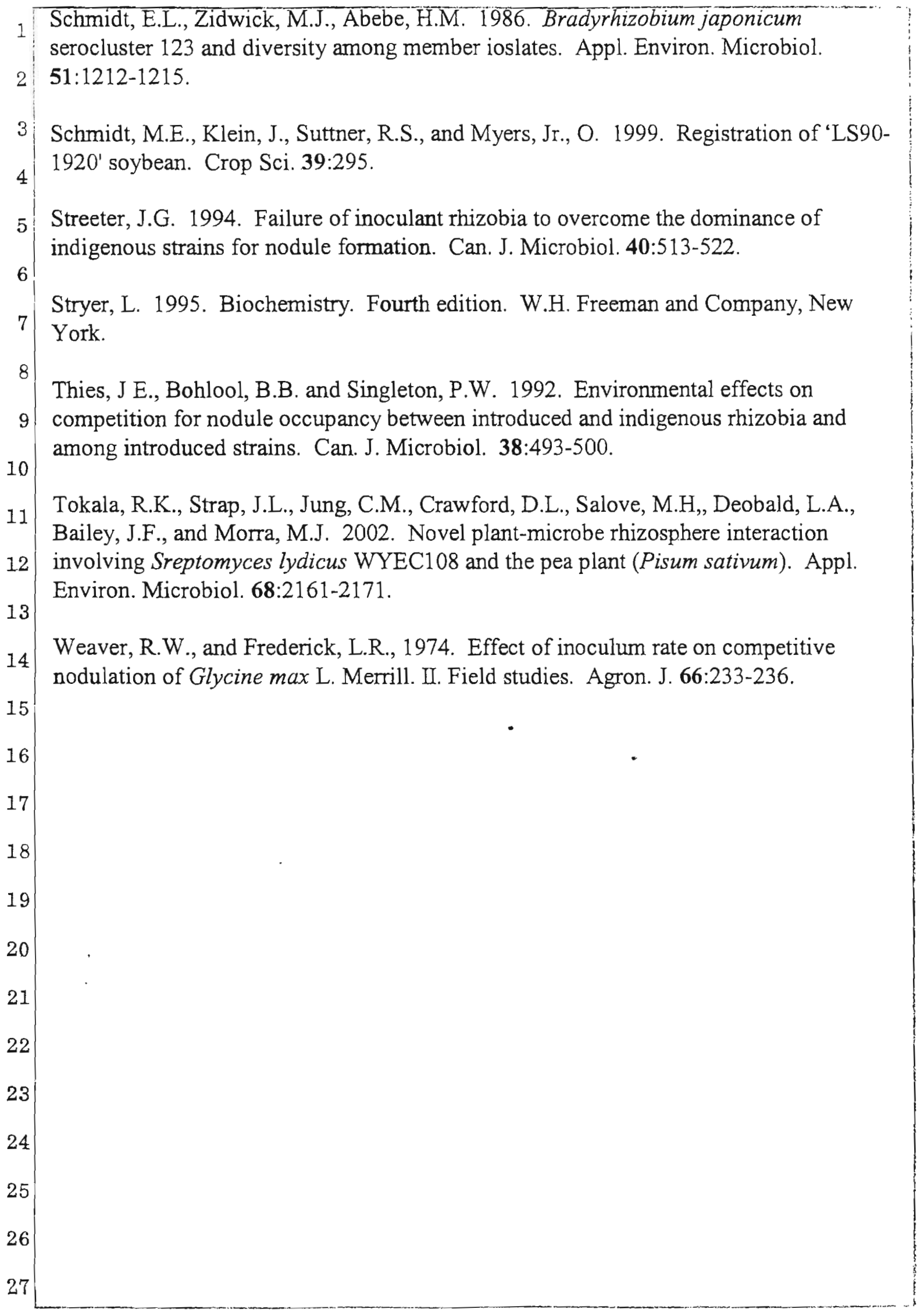


Table 1. Selected chemical properties of the soil (Stoy silt loam) used in the soil-pot coinoculation greenhouse study. ${ }^{\dagger}$

$\begin{array}{lllll}\begin{array}{l}\text { Sampling } \\ \text { location }\end{array} & \text { Soil pH } & \begin{array}{l}\text { Bray } \mathrm{P}_{1} \\ \text { Extractable } \mathrm{P}\end{array} & \text { Exchangeable K } & \begin{array}{l}\text { Organic } \\ \text { matter } \\ \text { content }\end{array} \\ & & -127 \pm 14 & 2.1 \pm 0.1\end{array}$

Values in table are means of five replicates \pm the standard deviation (SD). 
Table 2. Plate count of seed incoula for the soil-pot co-inoculation greenhouse study. ${ }^{\dagger}$

\begin{tabular}{lll}
\hline Inoculum treatment & count $\left(\log _{10} / \mathrm{ml}\right)$ & $\mathrm{CV}(\%)^{\ddagger}$ \\
\hline S. kanamycetius & $8.36 \pm 0.05$ & $0.6 \%$ \\
KNI-110-1 & $8.62 \pm 0.06$ & $0.7 \%$ \\
KNI-110-2 & $8.16 \pm 0.13$ & $1.6 \%$ \\
KNI-110-3 & $8.73 \pm 0.09$ & $1.0 \%$ \\
KNI-110-5 & $8.51 \pm 0.05$ & $0.5 \%$ \\
KN3I1B-2 & $8.63 \pm 0.08$ & $0.9 \%$ \\
KN3I1B-3 & $8.09 \pm 0.15$ & $1.9 \%$ \\
KT3I1B-1 & $8.87 \pm 0.06$ & $0.7 \%$ \\
KT3I1B-2 & $8.87 \pm 0.06$ & $0.7 \%$ \\
KT3I1B-3 & $8.63 \pm 0.04$ & $0.5 \%$ \\
\hline - & & \\
\hline
\end{tabular}

${ }^{\dagger}$ Values in table are means of three replicates \pm the standard deviation (SD)

$\ddagger$ Percent coefficient of variation. 
Table 3. Percent inhibition of $B$. japonicum from soybean nodules.

\begin{tabular}{llll} 
Antibiotic $^{\dagger}$ & $\mathrm{ARC}^{\ddagger}$ & $\mathrm{BRC}^{\ddagger}$ & Average \\
Kanamycin & $83.3 \mathrm{a}^{*}$ & $96.5 \mathrm{a}$ & 89.9 \\
Neomycin & $54.1 \mathrm{c}$ & $76.5 \mathrm{c}$ & 65.3 \\
Oxytetracycline & $71.4 \mathrm{~b}$ & $90.1 \mathrm{~b}$ & 80.8 \\
Rifampicin & $75.4 \mathrm{~b}$ & $73.5 \mathrm{c}$ & 74.0 \\
Tetracycline & $69.6 \mathrm{~b}$ & $95.3 \mathrm{ab}$ & 82.5 \\
\hline
\end{tabular}

${ }_{100} \mu \mathrm{g} / \mathrm{ml}$ growth medium

Values in table are means of 4,000 nodules

* Means in the same column followed by the sample letter are not significantly different $(\mathrm{P} \leq$ 0.05 ) according to the Duncan's Multiple Range Test 
Table 4. Percent inhibition of $B$.japonicum growth by antagonistic strains of actinomycetes.

\begin{tabular}{|c|c|c|c|c|c|c|c|c|}
\hline \multirow[b]{2}{*}{ Actinomycete } & \multicolumn{8}{|c|}{ Test Strain of $B$. japonicum ${ }^{\dagger}$} \\
\hline & $\begin{array}{l}\overline{\mathrm{I}}- \\
110\end{array}$ & $\begin{array}{l}3 \mathrm{I1B}- \\
110\end{array}$ & $\begin{array}{l}3 \mathrm{I} 1 \mathrm{~B}- \\
76\end{array}$ & $\begin{array}{l}3 \mathrm{I} 1 \mathrm{~B}- \\
24\end{array}$ & $\begin{array}{l}\mathrm{An} \\
5\end{array}$ & 123 & 127 & Average \\
\hline & \multicolumn{8}{|c|}{ - Inhibition- } \\
\hline A. mediterranei & $3.3 c^{*}$ & $0 \mathrm{c}$ & $10.0 \mathrm{a}$ & $43.3 \mathrm{bc}$ & $6.7 \mathrm{ab}$ & $10.0 \mathrm{ab}$ & $3.3 b$ & 9.2 \\
\hline S. coeruleoprunis & $23.3 \mathrm{~b}$ & $26.7 \mathrm{ab}$ & $13.3 \mathrm{a}$ & $76.7 \mathrm{a}$ & $10.0 \mathrm{a}$ & $6.7 \mathrm{a}$ & $10.0 \mathrm{a}$ & 22.0 \\
\hline S. kanamycetius & $46.7 \mathrm{a}$ & $40.0 \mathrm{a}$ & $13.3 \mathrm{a}$ & $36.7 \mathrm{c}$ & $10.0 \mathrm{a}$ & $6.7 \mathrm{~b}$ & $13.3 \mathrm{a}$ & 20.4 \\
\hline S. rimosus & $23.3 b$ & $13.3 b$ & $13.3 \mathrm{a}$ & $76.7 \mathrm{a}$ & $\mathrm{Ob}$ & $20.0 \mathrm{a}$ & $0 \mathrm{~b}$ & 19.6 \\
\hline S. species & $10.0 \mathrm{bc}$ & $13.3 b$ & $\mathrm{Ob}$ & $60.0 \mathrm{ab}$ & $6.7 \mathrm{ab}$ & $0 \mathrm{c}$ & $\mathrm{Ob}$ & 10.4 \\
\hline
\end{tabular}

${ }^{\dagger}$ Three replications per strain.

* Means in the same column followed by the same letter are not significantly different $(\mathrm{P} \leq 0.05)$ according to the Duncan Multiple Range Test. 
Table 5. Symbiotic characteristics of selected antibiotic resistant strains of $B$. japonicum: competence study.

\begin{tabular}{|c|c|c|c|c|c|}
\hline B. japonicum & $\begin{array}{l}\text { Trial } \\
\text { Number }\end{array}$ & $\begin{array}{l}\text { Nodule } \\
\text { Number }\end{array}$ & $\begin{array}{l}\text { Nodule } \\
\text { Occupancy }^{\dagger}\end{array}$ & $\begin{array}{l}\text { Shoot N } \\
\text { Content }\end{array}$ & $\begin{array}{l}\text { Acetylene } \\
\text { Reduction } \\
\text { Activity }\end{array}$ \\
\hline & & & $\ldots \%$ & $-\%$ & $\begin{array}{c}-\mu \mathrm{mol} \mathrm{C}_{2} \mathrm{H}_{4} \\
\text { plant/hr-- }\end{array}$ \\
\hline Parental Strain (3I1b-110) & 0) 1 & $44 a b^{*}$ & $10 \mathrm{~b}$ & $2.38 \mathrm{a}^{\ddagger}$ & $3 a b$ \\
\hline $\mathrm{KN} 311 \mathrm{~B}-2$ & & $40.2 \mathrm{ab}$ & $80 \mathrm{a}$ & $2.10 \mathrm{ab}$ & $3 a b$ \\
\hline KN3I1B-3 & & $31.2 \mathrm{bcd}$ & $95.9 \mathrm{a}$ & $1.91 \mathrm{abc}$ & $3 a b$ \\
\hline Parental Strain (I-110) & & $50 \mathrm{a}$ & $\mathrm{Ob}$ & $2.43 a$ & $1 \mathrm{~b}$ \\
\hline KNI-110-1 & & $31 \mathrm{bcd}$ & $98.6 \mathrm{a}$ & $1.38 \mathrm{cde}$ & $5 \mathrm{a}$ \\
\hline KNI-110-2 & & 37 abcd & $97.3 \mathrm{a}$ & $1.19 \mathrm{e}$ & $5 a$ \\
\hline KNI-110-3 & & $29 \mathrm{~cd}$ & $100 \mathrm{a}$ & $1.53 \mathrm{cde}$ & $6 a$ \\
\hline KNI-110-5 & & $23 d$ & $100 \mathrm{a}$ & $1.05 \mathrm{e}$ & $4 \mathrm{a}$ \\
\hline Parental Strain (3I1B-110 & 0) 2 & 22 & $\mathrm{Ob}$ & $2.04^{\S}$ & 59 \\
\hline KT3I1B-1 & & 32 & $100 \mathbf{a}$ & 2.23 & 72 \\
\hline KT3I1B-2 & & 26 & $19.4 b$ & 2.17 & 88 \\
\hline KT3I1B-3 & & 25 & $\mathrm{Ob}$ & 2.11 & 94 \\
\hline & & $\mathrm{NS}^{\uparrow}$ & & NS & NS \\
\hline
\end{tabular}

${ }_{\text {Number of plated nodules (out of 16) that were positive for growth on YEM agar supplemented }}$ with $100 \mu \mathrm{g} / \mathrm{ml}$ (each of kanamycin + neomycin $(\mathrm{KN})$ or kanamycin + tetrcycline $(\mathrm{KT})$.

${ }^{\ddagger}$ Data (Trial 1) normalized for biological fixed $\mathrm{N}$ by subtracting the shoot $\mathrm{N}$ content of the noninoculated control, $(0.89 \%)$, from the inoculated treatment.

${ }^{\S}$ Data (Trial 2) normalized for biological fixed $\mathrm{N}$ by subtracting the shoot $\mathrm{N}$ content of the noninoculated control, (1.01\%), from the inoculated treatment.

* Means in the same column followed by the same letter are not significantly different $(\mathrm{P} \leq 0.05)$ according to the Duncan Multiple Range Test.

NS $=$ Non-significant 
Table 6. Nodule number, nodule occupancy, and shoot $\mathrm{N}$ content of selected antibiotic resistant strains of $B$. japonicum: soil-pot co-inoculation greenhouse study.

\begin{tabular}{|c|c|c|c|c|}
\hline \multirow[b]{2}{*}{ Inoculum Treatment } & \multirow{2}{*}{$\begin{array}{l}\text { Nodule } \\
\text { Number }\end{array}$} & \multicolumn{2}{|c|}{ Nodule Occupancy } & \multirow{2}{*}{$\begin{array}{l}\text { Shoot N } \\
\text { Content }\end{array}$} \\
\hline & & $\mathrm{KN}$ & $\mathrm{KT}$ & \\
\hline & & \multicolumn{2}{|c|}{ - } & ----\% \%-- \\
\hline Non-Inoculated Control & $28 b^{*}$ & $6.1 \mathrm{~b}$ & $a b$ & $2.50 \mathrm{efg}$ \\
\hline N Fertilizer Control & $6 \mathrm{c}$ & $\mathrm{ND}^{+}$ & ND & $3.97 \mathrm{a}$ \\
\hline S. kanamycetius & $31 \mathrm{~b}$ & $11.4 \mathrm{~b}$ & $6.3 \mathrm{ab}$ & $2.43 \mathrm{efg}$ \\
\hline KNI-110-1 & $28 \mathrm{~b}$ & $1.0 \mathrm{~b}$ & - & $2.29 \mathrm{~g}$ \\
\hline KNI-110-2 & $46 a$ & $5.2 b$ & - & $2.56 \mathrm{efg}$ \\
\hline KNI-110-3 & $31 \mathrm{~b}$ & $3.3 b$ & - & $2.21 \mathrm{~g}$ \\
\hline KNI-110-5 & $29 b$ & $6.6 b$ & - & $2.41 \mathrm{fg}$ \\
\hline $\mathrm{KN} 311 \mathrm{~B}-2$ & $32 b$ & $\mathrm{Ob}$ & - & $2.40 \mathrm{fg}$ \\
\hline KN3I1B-3 & $28 b$ & $19.6 b$ & - & $2.99 \mathrm{bcd}$ \\
\hline S. kanamycetius + KNI-110-1 & $28 \mathrm{~b}$ & $44.8 \mathrm{a}$ & - & $3.13 b c$ \\
\hline S. kanamycetius + KNI-110-2 & $32 b$ & $14.1 \mathrm{~b}$ & - & $2.81 \mathrm{cde}$ \\
\hline S. kanamycetius + KNI-110-3 & $29 b$ & $12.0 \mathrm{~b}$ & - & $2.40 \mathrm{fg}$ \\
\hline S. kanamycetius + KNI-110-5 & $32 b$ & $48.0 \mathrm{a}$ & - & $2.77 \mathrm{cdef}$ \\
\hline S. kanamycetius + KN3I1B-2 & $26 \mathrm{~b}$ & $55.0 \mathrm{a}$ & - & $3.05 \mathrm{bcd}$ \\
\hline S. kanamycetius + KN3I1B-3 & $24 b$ & $16.4 \mathrm{~b}$ & - & $2.41 \mathrm{fg}$ \\
\hline KT3I1B-1 & $35 b$ & - & $12.2 \mathrm{ab}$ & $3.21 \mathrm{~b}$ \\
\hline KT3I1B-2 & $35 b$ & - & $18.3 \mathrm{a}$ & $3.07 \mathrm{bc}$ \\
\hline KT3I1B-3 & $32 b$ & - & $10.4 \mathrm{ab}$ & $2.30 \mathrm{~g}$ \\
\hline S. kanamycetius + KT3I1B-1 & $28 b$ & - & $16.3 a$ & $2.43 \mathrm{fg}$ \\
\hline S. kanamycetius + KT3I1B-2 & $30 \mathrm{~b}$ & - & $4.7 \mathrm{ab}$ & $2.40 \mathrm{fg}$ \\
\hline S. kanamycetius + KT3I1B-3 & $28 \mathrm{~b}$ & - & $14.4 \mathrm{a}$ & $3.24 \mathrm{~b}$ \\
\hline
\end{tabular}

* Means in the same column followed by the same letter are not significantly different $(\overline{\mathrm{P} \leq 0.05)}$ according to the Duncan Multiple Range Test.

${ }^{\top} \mathrm{ND}=$ No Data. 